\title{
The Effects of Postsynaptic Levels of Cyclic AMP on Excitatory and Inhibitory Responses of an Identified Central Neuron
}

\author{
Laura R. Wolszon ${ }^{1}$ and Donald S. Faber ${ }^{2}$ \\ 'Department of Biophysical Sciences, and '2Department of Physiology, State University of New York at Buffalo, \\ Buffalo, New York 14214
}

\begin{abstract}
The effects of cAMP on Mauthner (M-) cell excitatory and inhibitory responses were studied in vivo. Cyclic AMP was iontophoresed into the $M$-cell lateral dendrite, after which we monitored the changes in cellular responsiveness to stimulation of 2 classes of identified presynaptic cells: (1) excitatory fibers from the posterior branch of the ipsilateral eighth cranial nerve and (2) inhibitory interneurons activated by the $\mathrm{M}$-cell collateral and commissural networks. We found that postsynaptic injections of CAMP increased the magnitudes of the electrically and chemically mediated EPSPS from the eighth nerve and enhanced M-cell inhibitory responses as well. Furthermore, cAMP augmented paired-pulse facilitation of both types of excitatory potentials. No effects on input conductance, resting membrane potential, or presynaptic spike width were observed. All effects were mimicked by aminophylline, a CAMP-dependent phosphodiesterase inhibitor but not by 5'-AMP, the CAMP breakdown product. These results provide evidence for second-messenger modulation in vivo of electrotonic and chemical synaptic potentials at mixed synapses. In addition, they provide the first evidence for CAMP modification of a glycinergic receptor-channel complex. Preliminary results from some of these experiments have been reported previously (Wolszon and Faber, 1986).
\end{abstract}

Second-messenger systems play a substantial role in the control of a variety of neuronal functions, such as synaptic efficacy, excitability, metabolism, and structural organization. In particular, agents that are involved in the cAMP-dependent protein kinase pathway are known to have profound effects on synaptic transmission. At chemical synapses, there are numerous reports of cAMP-dependent enhancements of synaptic efficacy, either through the augmentation of transmitter release or by the modification of postsynaptic receptor or channel properties (for reviews, see Browning et al., 1985; Kaczmarek and Levitan, 1987). In contrast, the role of cAMP in the regulation of electrotonic coupling between neurons is less well understood. Although there is a great deal of evidence from non-neuronal systems such as heart, liver, and epithelium that elevated levels of cAMP

\footnotetext{
Received Mar. 22, 1988; revised Aug. 11, 1988; accepled Aug. 12, 1988.

This work was supported in part by NIH Grant NS 21848. We wish to thank Julie Lakatos and Prince J. Brown for assistance with the graphics, Mrs. Jean Seiler for assistance with the typing, and Joseph R. Fetcho and David R. Bender for comments on an earlier version of the manuscript.

Correspondence should be addressed to Dr. Donald S. Faber, Department of Physiology, State University of New York, 313 Cary Hall, Buffalo, NY 14214. Copyright (C) 1989 Society for Neuroscience $0270-6474 / 89 / 030784-14 \$ 02.00 / 0$
}

increase both the conductance of gap junctions and the number of electrotonic junctions formed (see Spray and Bennett, 1985), the effects of cAMP on neuronal coupling have been studied in only 2 preparations thus far. Specifically, (1) Kessler et al. (1984) found that cAMP increases the incidence of formation of gap junctions in cultured neonatal rat sympathetic neurons, and (2) elevated levels of cAMP have been found to decrease the conductance through electrotonic junctions in retinal horizontal cells (Piccolino et al., 1982; Teranishi et al., 1982; Lasater and Dowling, 1985). Similarly, information relating to the modification of inhibitory synapses is also somewhat limited; while a great deal is now known about modulatory mechanisms regulating the function of the GABA receptor-channel complex (for review, see Bormann, 1988), comparable information relating to glycine, the other classical inhibitory transmitter, is lacking.

In an attempt to better understand some of the mechanisms by which cAMP modifies synaptic interactions between vertebrate central neurons, we have taken advantage of the unique morphological organization of inputs to the goldfish Mauthner (M-) cell to study the effects of intracellular postsynaptic injections of cAMP on neuronal responses. Postsynaptic potentials from 2 classes of identified presynaptic neurons were examined, one type being excitatory to the M-cell and the other inhibitory. The excitatory fibers originate in the posterior branch of the ipsilateral eighth cranial nerve (hereafter referred to as "VIIIthN" or "saccular nerve") and monosynaptically carry auditory information to the M-cell via synapses that are morphologically mixed. Stimulation of this nerve produces both chemical and electrotonic postsynaptic potentials in the M-cell (Furshpan, 1964). The glycinergic inhibitory interneurons, often referred to as PHP cells (Korn and Faber, 1976), arise from 2 separate pathways, one being the $M$-cell recurrent collateral network and the other being the disynaptic inhibitory network of the saccular nerve (Faber and Korn, 1978). The M-cell system therefore permits the investigation of the effects of elevating postsynaptic levels of cAMP on three types of synaptic responses: chemical and electrical EPSPs and glycinergic IPSPs. We have found that intracellular injections of cAMP into the M-cell enhance each of these responses. Although the effects on excitation are generally consistent with those observed in other systems, the data on inhibition represent the first time that cAMP has been shown to modify a glycinergic receptor-channel complex.

\section{Materials and Methods}

Four- to five-inch goldfish were anesthetized with MS-222 and paralyzed with $d$-tubocurarine hydrochloride $(3 \mu \mathrm{g} / \mathrm{gm}$ body weight). The preparation and general physiological techniques were similar to those described previously (Korn and Faber, 1975; Faber and Korn, 1978; Lin and Faber, 1988a). A bipolar stimulating electrode on the spinal cord 
was used to antidromically activate the $\mathrm{M}$-cell and assist in its localization (Furshpan and Furukawa, 1962). For orthodromic activation, a 10-20 M $\Omega$ microstimulating bipolar electrode with tip diameters of approximately $10 \mu \mathrm{m}$ was placed on the saccular nerve, about $800 \mu \mathrm{m}$ outside the brain (Lin, 1986; Lin and Faber, 1988a). This electrode was insulated except at the very tips, which were offset relative to each other and scparatcd by approximatcly $100 \mu \mathrm{m}$ to permit finc control of stimulus location and strength.

The M-cell was penetrated with microelectrodes filled with either (1) $2 \mathrm{M} \mathrm{KCl}, 4 \mathrm{M} \mathrm{KAc}$, or $0.5 \mathrm{M} \mathrm{K}_{2} \mathrm{SO}_{4}$, (2) one of the above with $20 \mathrm{~mm}$ Tris-base added (hereafter referred to as "vehicle"), (3) $200 \mathrm{mM}$ cAMP and $10 \mathrm{~mm}$ aminophylline (or either one alone) in vehicle, or (4) 200 $\mathrm{mM} 5^{\prime}$-AMP in vehicle. All electrode solutions were adjusted to a final $\mathrm{pH}$ of 7.6-7.8. Electrode resistances varied from 3 to $30 \mathrm{M} \Omega$, depending upon the filling solution. Generally, drugs and the anions in the vehicle were iontophoretically injected for $3-5 \mathrm{~min}$ at -100 to $-190 \mathrm{nA}$. Occasionally, pressure injections were used instead of iontophoresis, but the choice of injection method had no apparent effect on the outcome of the experiments. Because M-cell IPSPs are chloride-dependent, and the chloride ion concentration is normally at equilibrium at the resting potential (Furshpan and Furukawa, 1962; Fabcr and Korn, 1982), M-cell inhibitory responses are usually detected only as a conductance changes rather than as clear IPSPs. Therefore, to determine whether IPSPs influenced by cAMP were chloride-dependent, the drug electrode was inserted into the lateral dendrite while a second electrode, containing $2.5 \mathrm{M} \mathrm{KCl}$ and used for steady-state chloride-loading of the cell, was placed in the soma. In some cases, the strychnine sensitivity of these IPSPs was assessed by iontophoresing $40 \%$ saturated strychnine sulfate in $2.5 \mathrm{M} \mathrm{KCl} \mathrm{(pH} \mathrm{3)} \mathrm{into} \mathrm{the} \mathrm{M}$-cell axon cap for 5-10 min at $100-300$ nA.

All control records were taken at least $10 \mathrm{~min}$ after the M-cell penetration had stabilized, as indicated by the constancy of the neuron's antidromic spike, resting membrane potential, and responses to VIIIth-N inputs. The time course of the drug effects was referenced to the moment that iontophoresis was terminated. Data were digitized and averaged on-line with a Nicolet 1074 signal averager and were recorded on film or tape for subsequent, more detailed analysis. Taped records were digitized and analyzed on a DEC LSI/1 1-73 computer connected to an INDEC data-acquisition system.

Aminophylline ([theophylline] $]_{2}$ ethylenediamine), cAMP (adenosine 3':5'-cyclic monophosphate, sodium salt), 5'-AMP (adenosine 5'-monophosphate), strychnine sulfate, and MS-222 (ethyl m-aminobenzoate) were obtained from Sigma Chemical Co., and tubocurarine chloride from E. R. Squibb and Sons, Inc.

\section{Results}

\section{Effects of cAMP on M-cell excitatory responses}

The excitatory saccular fibers terminate on the distal portion of the $\mathrm{M}$-cell lateral dendrite primarily as large, myelinated club endings (Fig. 1 $A$ ). All of these endings possess morphological specializations consistent with both chemical and electrotonic modes of synaptic transmission (Robertson, 1963; Robertson et al., 1963; Nakajima, 1974; Kohno and Noguchi, 1986; Tuttle et al., 1986). Physiological recordings indicate, however, that although every club ending is electrotonically coupled to the M-cell, evoked transmitter release can normally be detected from only $20 \%$ of the activated saccular fibers (Lin and Faber, 1988a). These fibers first contact the dendrite approximately $250 \mu \mathrm{m}$ from the cell body (Lin et al., 1983). For all the experiments described in this section, a recording and injecting microelectrode was inserted just proximal to that region to maximize the amplitudes of the 2 components of the VIIIth-Nevoked responses and to allow iontophoresed agents easy access to the postsynaptic membrane apposed to the terminals.

To determine whether cAMP affects M-cell responses to excitatory inputs, we first recorded the cell's response to a particular VIIIth-N stimulus strength, then iontophoresed cAMP into the M-cell lateral dendrite, and subsequently monitored the cell's response to the same stimulus strength. We found that
cAMP produced an enhancement of both the electrical and chemical EPSPs. An example of these effects is given in Figure $1 B$. The upper-left panel shows a typical subthreshold M-cell response to stimulation of the ipsilateral saccular nerve, before injection of cAMP. The short-latency electrical potential ("e"), arising from current flow through the gap junctions of the club endings (Furshpan, 1964), is characterized by its rapid rates of rise and decay. It is followed by a slower and smaller chemically mediated EPSP ("c"), originating from the same saccular fibers (Lin and Faber, 1988b). The amplitude of the electrotonic potential (approximately $14 \mathrm{mV}$ in this experiment) can be used to provide a rough estimate of the number of saccular fibers that are activated at a given stimulus strength: Since a single VIIIth-N fiber produces, on the average, an electrical EPSP of $0.83 \mathrm{mV}$ (Lin and Faber, 1988a), about 18 fibers were stimulated in this case. The upper-right panel of Figure $1 B$ shows the enhancement of the M-cell responses following an injection of 200 mM cAMP plus $10 \mathrm{~mm}$ aminophylline (a hydrophilic cAMPdependent phosphodiesterase inhibitor) in a KAc vehicle. These responses were recorded approximately $7 \mathrm{~min}$ after exposure to the drug and indicate that cAMP augmented the electrically and chcmically mediatcd EPSPs by 17 and 58\%, respectively.

One possible explanation of the finding that cAMP enhanced the amplitudes of both types of EPSPs was that it increased the resting input resistance of the $\mathrm{M}$-cell. Two types of measurements indicate that this was not the case. The first involved direct measures of the transfer resistance (before and after cAMP), which, because of the difficulty in maintaining a 2-electrode penetration for a long period of time, were only possible in 4 cases. In those instances, cAMP slightly decreased resting input resistance by an average of $11 \%$, from 132 to $118 \mathrm{~K} \Omega$. The second measure takes advantage of the fact that the M-cell soma and lateral dendrite do not support active spike electrogenesis (Furshpan and Furukawa, 1962; Diamond, 1968; Faber and Korn, 1978), meaning that the amplitude of the antidromically evoked action potential could be used as an indicator of whether the cell's input resistance had changed following drug injection. The lower 2 panels in Figure $1 B$ illustrate the antidromic spikes recorded immediately after the corresponding synaptic responses (upper traces). The slight drop in the spike amplitude $(\sim 4 \%)$ following injection indicates a small decrease in input resistance. For this study, experiments were disregarded if their antidromic spike heights dropped by more than $15 \%$, as this effect was taken as being indicative of damage. The resting membrane potential was unaffected by cAMP-aminophyllinc in this and in all other experiments described in this report.

To test whether the effects seen on the VIIIth-N responses were an artifact of iontophoresis, we performed control injections of vehicle without cAMP or aminophylline. Figure $2 \mathrm{~A}$ illustrates that the vehicle did not augment either the electrical or chemical EPSP; in this example, the responses were actually somewhat diminished by the injection. Furthermore, constant antidromic spike amplitude and resting membrane potential indicated that passive membrane properties were unaffected (not shown). These results were obtained in 8 out of 10 control experiments and were independent of the choice of vehicle or the length of time of injection.

Because cAMP-dependent phosphodiesterase hydrolyzes cAMP to 5'-AMP and hydrogen ion, we tested the possibility that the effects we saw with cAMP injections were actually due to the action of 5 -AMP. In 9 cxpcriments, we injected 5'-AMP in vehicle with the same injection parameters and in the same 

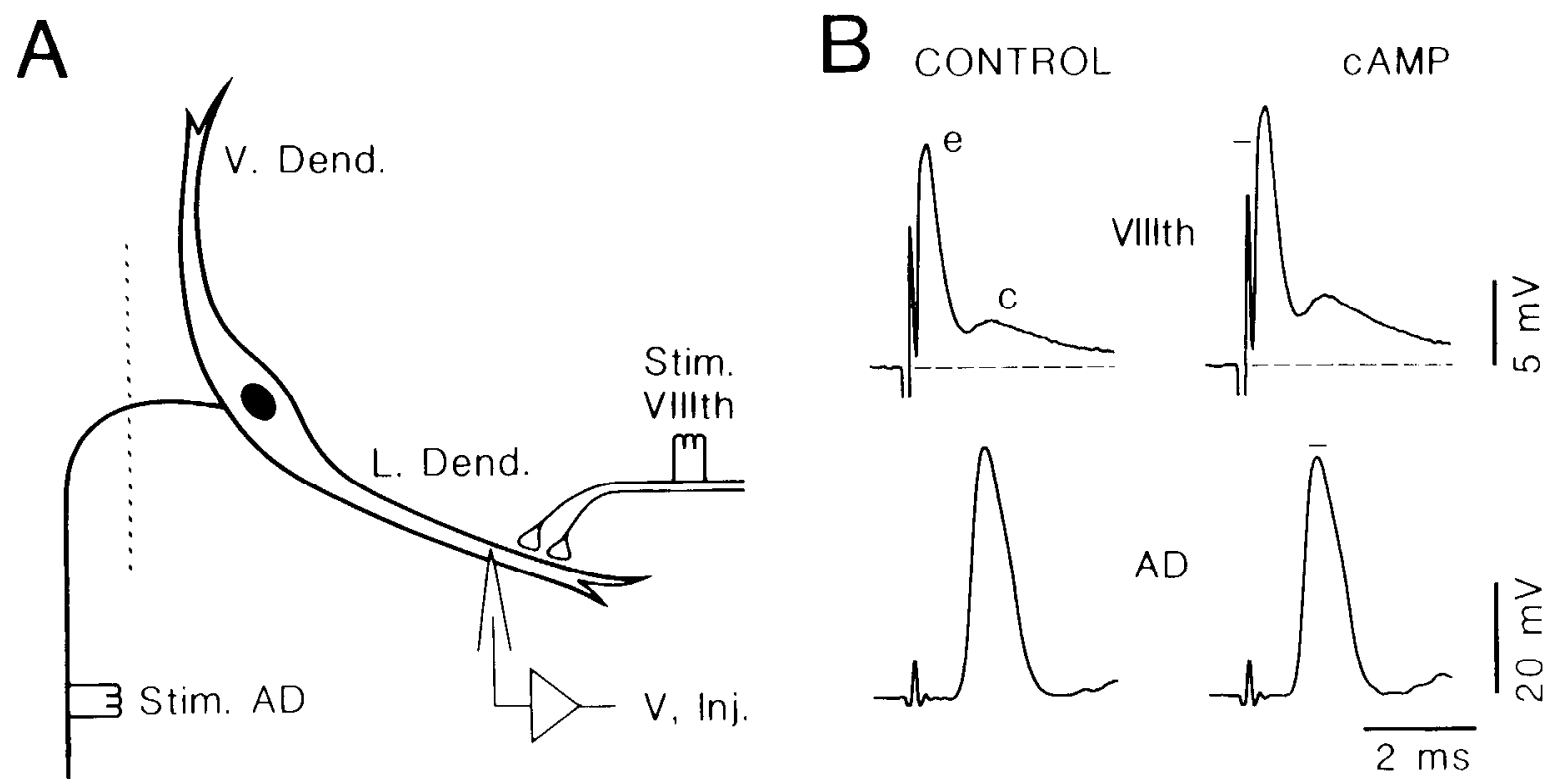

Figure 1. Cyclic AMP enhances Mauthner cell excitatory responses. A, Schematic drawing of one Mauthner Cell (M-cell), projected onto a horizontal plane. The cell was activated (1) orthodromically, by stimulation of the ipsilateral VIIIth nerve (Stim. VIIIth), which is excitatory to the distal lateral dendrite ( $L$. Dend.), and (2) antidromically, by stimulation of the M-cell axon in the spinal cord (Stim. AD). Intradendritic recordings werc obtaincd from and iontophoretic injections performed with the same microclectrode, inserted 150-225 $\mu \mathrm{m}$ from the M-cell body ( $V$, Inj.). $V$. Dend. labels the ventral dendrite; the dashed line represents the midline. $B$, Upper traces: Intradendritic recordings of VIIIth nerve (VIIIth- $N$ ) EPSPs before and after iontophoretic injection of cAMP-aminophylline. Both the electrical EPSP $(e)$ and the chemical EPSP $(c)$ were augmented. Dashed line indicates baseline; bar indicates preinjection electrotonic potential amplitude. Lower traces: Antidromically evoked action potentials, recorded immediately after each of the above VIIIth-N stimulations. Slight reduction in spike height after cAMP (compare with bar) indirectly indicates at most a small reduction of $\mathrm{M}$-cell resting input resistance. Resting membrane potential was unchanged (not shown). All traces are averages of 10 or more sweeps.

concentration as for the cAMP experiments. There were only small effects of this compound on both the electrotonic and the chemical EPSPs, as shown in Figure $2 B$. In this example, $5^{\prime}-$ AMP decreased the electrotonic PSP by $3 \%$ and increased the chemical one by $3 \%$. The possibility that cAMP exerts its effects through its breakdown product is therefore unlikely.

The question remained as to whether cAMP was an endogenous regulator of $\mathrm{M}$-cell activation, or if it merely acted as a foreign promoter of changes in responsiveness. We addressed this issue in 5 experiments, in which we injected aminophylline alone, under the assumption that it would only mimic cAMP effects if a baseline level of cAMP were maintained in the cell by a significant rate of synthesis and hydrolysis. The results obtained with aminophylline were qualitatively identical to those with CAMP, though of somewhat smaller amplitude. An example is shown in Figure $2 C$. In this case, the electrotonic and chemical EPSPs were increased by 22 and $74 \%$, respectively. There were, again, no changes in antidromic spike height or resting membrane potential (not shown). We therefore conclude that cAMP is an endogenous modulator of M-cell responsiveness to VIIIth-N inputs.

\section{Statistical analysis}

Results similar to those shown in Figures $1 B$ and $2 C$ were found in 29 out of 32 experiments, although the magnitudes of the enhancements varied appreciably. For purposes of statistical analysis, all data were subjected to the Mann-Whitney test, to establish if there was a statistically significant correlation between the injection of drugs and the enhancement of the re- sponses. This test determines whether the medians of 2 data sets (which are not normally distributed) are significantly different from each other. The data from the 32 experiments involving cAMP, aminophylline or both were pooled and compared with 10 in which we injected vehicle alone. For experiments in which more than one VIIIth-N stimulus strength was used, all values were averaged before proceeding with the analysis, since we noted that the outcomes of the injections were not related to the baseline values of the electrotonic and chemical potentials. The analysis indicated that cAMP-aminophylline enhanced the VIIIth-N electrically mediated EPSPs by a median of $0.84 \mathrm{mV}(n=32)$, while the vehicle injections decreased this response by $0.31 \mathrm{mV}(n=10)$. These values are significantly different at the 0.0155 level. Similarly, cAMP-aminophylline increased chemical EPSPs by a median of $0.47 \mathrm{mV}(n=32)$, compared with a decrease after vehicle injection of $0.14 \mathrm{mV}(n$ $=10$ ), this difference being significant at the 0.0082 level. The average values of the electrical and chemical potentials before injection were 5.20 and $2.04 \mathrm{mV}$, respectively, for the drug experiments, and 8.36 and $3.87 \mathrm{mV}$ for the controls. This analysis provides a conservative measure of the cAMP effects; the enhancements were at times as large as $200-500 \%$ relative to preinjection values (see Figs. 3 and 4). In the nine 5'-AMP experiments, the electrotonic and chemical potentials increased by a median of 0.22 and $0.20 \mathrm{mV}$ from control values of 13.91 and $4.15 \mathrm{mV}$, respectively. These effects are statistically indistinguishable from those of vehicle, being significant at only the 0.2888 level for both the electrotonic and chemical potentials. Statistical values are not given for the effects of aminophylline alone because of the small sample size. 


\section{Effects on paired-pulse facilitation}

In a number of systems, when 2 presynaptic stimuli are paired at a sufficiently short interval, the second of the 2 resulting EPSPs is significantly larger than the first. This phenomenon of paired-pulse facilitation occurs at the junctions between the saccular fibers and the $\mathrm{M}$-cell and has been attributed to an increase in transmitter release following a second presynaptic action potential (Lin and Faber, 1988b). Because of the large effects of cAMP on a single EPSP, we investigated the possibility that cAMP might also enhance facilitation. Facilitation was estimated using the expression:

$$
\% \text { Facilitation }=\left[\left(\text { Response }_{2}-\text { Response }_{1}\right) /\right.
$$$$
\text { (Response } \left.\left.{ }_{1}\right)\right] 100 \% \text {. }
$$

There was a striking cAMP-induced enhancement of facilitation of the chemically mediated EPSPs in several experiments. In addition, the electrical EPSPs sometimes exhibited a pairedpulse facilitation that could be enhanced by cAMP injections. These effects on the 2 different types of facilitation could not be evaluated statistically, however, both because of the limited number of experiments in which there were positive levels of facilitation bcforc injection and, pcrhaps morc importantly, bccause the second response was superimposed upon an VIIIth-N IPSP, which was also enhanced by cAMP (see below). The enhanced facilitations of the electrical and chemical EPSPs were, nevertheless, often quite large, and usually occurred independently of each other, as illustrated in Figure 3. In this experiment, $200 \mathrm{mM}$ cAMP in $4 \mathrm{M} \mathrm{KAc}$ was injected twice into the M-cell lateral dendrite (4.5 min per injection at $-190 \mathrm{nA}$, $10 \mathrm{~min}$ interval between injections), and the responses to VIIIth-N stimulation were monitored over time. The electrical potentials and chemical EPSPs evoked by single and paired pulses are superimposed in the figure to reveal the amplitudes of the second (conditioned) response. Prior to cAMP ("Control"), there was no apparent facilitation of the chemical EPSP, but the second electrical potential was slightly larger (about 5\%) than the first. Two minutes after the first injection, the conditioning electrical and chemical EPSPs were enhanced as expected, while paired-pulse facilitation grew to $11 \%$ facilitation for the electrotonic potential and $2 \%$ facilitation for the chemical EPSP. Each of these 3 effects became much more pronounced following the second injection: The electrotonic and chemical facilitations peaked at 20 and $50 \%$, respectively. Ten minutes after the second injection, the electrotonic and chemical responses to the first stimulus were increased by 114 and $195 \%$ of their original amplitudes, respectively, although the pairedpulse facilitations dropped to negligible levels. Therefore, as the conditioning responses grew, facilitation was at first also dramatically enhanced but then effectively disappeared. Other experiments showed cAMP increasing the electrotonic facilitation by up to 25 percentage points, while increasing chemical EPSP facilitation by up to 65 percentage points.

\section{Effects on presynaptic spike width}

We examined the possibility that postsynaptic injections of cAMP may have increased chemically mediated EPSPs presynaptically via spike broadening in the saccular fibers. This is conceivable because Lin and Faber (1988b) demonstrated that spike broadening, induced by intra-axonal injections of cesium or 4-AP, can increase both the incidence and the amplitude of transmitter release from the saccular fibcrs. Furthermorc, cAMP has a sufficiently low molecular weight to cross gap junctions (Simpson
A

\section{VEHICLE}

Control Inject
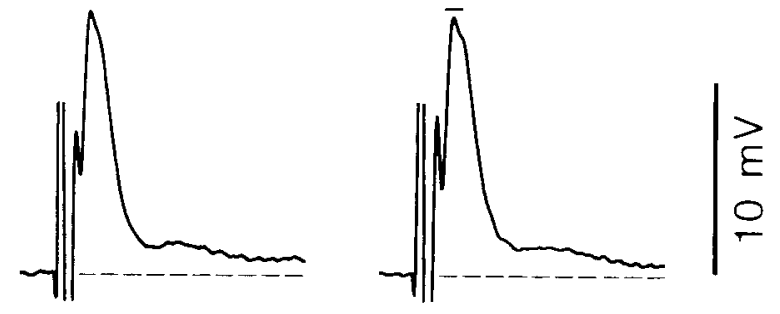

$\mathrm{B}$

5'-AMP

Control

Inject
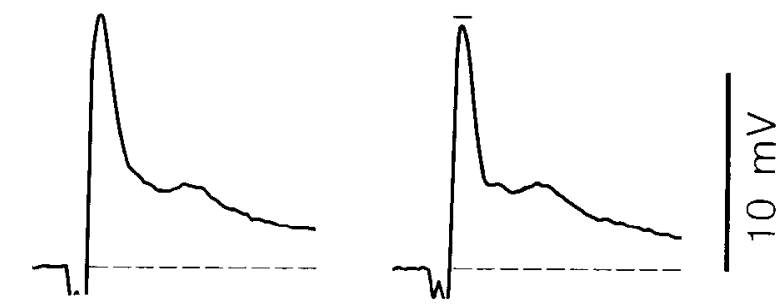

C

AMINOPHYLLINE
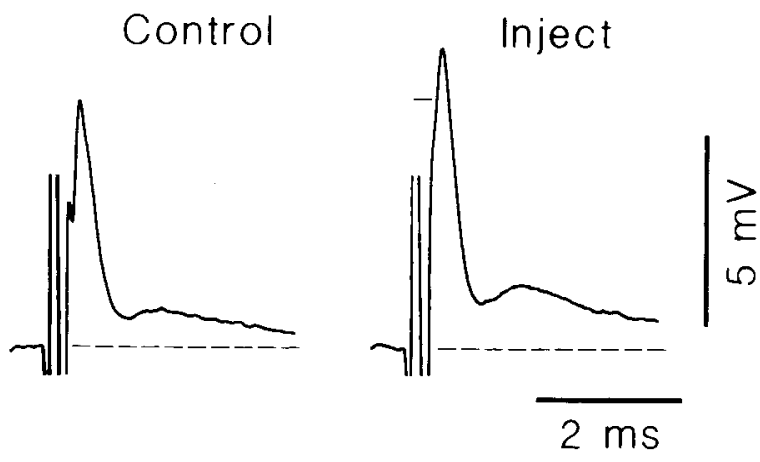

Figure 2. Evidence that the cAMP effects are specific. $A$, Injection of vehicle had no effect on either the electrically or chemically mediated EPSPs. The bar indicates the preinjection amplitude of the electrotonic potential. $B$, In another experiment, injection of $5^{\prime}$-AMP did not augment either type of EPSP. $C$, Data from a third experiment, indicating that the effects of aminophylline mimicked those seen with cAMP. Both the electrical potential and the chemical EPSP were augmented, as was paired-pulse facilitation (not shown). All traces are the averages of 10 or more sweeps.

et al., 1977; Flagg-Newton et al., 1979; Flagg-Newton, 1980; Schwartzmann et al., 1981) and thus reach the terminals of the saccular fibers. In these experiments, the duration of the electrically mediated EPSP was assumed to be indicative of that of the presynaptic spike (Lin and Faber, 1988a, b).

Presynaptic spike width, as inferred from the width of the electrical EPSP, was found to be unaffected by cAMP, even when large increases in electrical or chemical EPSPs occurred. This is demonstrated in Figure 4, in which we scaled the amplitude of the preinjection response to match that after the drug and then expanded the 2 in time so that their half-widths could be 

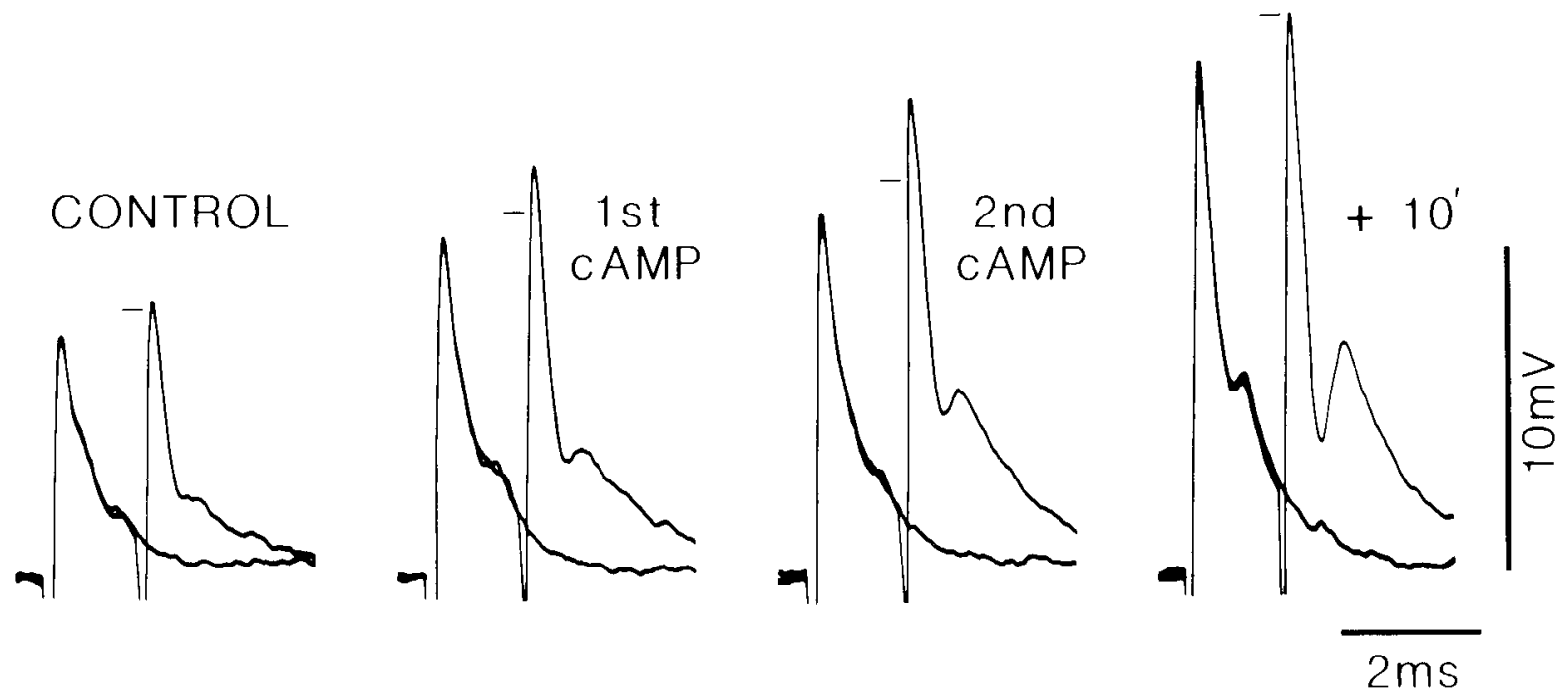

Figure 3. Effects of sequential injections of cAMP on the facilitation of both the chemical EPSP and the electrotonic potential. The ipsilateral $\mathrm{M}$-cell was injected twice with cAMP and monitored over time. Superimposed responses to single and paired VIIIth-N stimulations reveal a steady growth in the first electrical and chemical EPSPs as well as an even larger augmentation of the second. Each horizontal bar indicates the expected amplitude of the second electrotonic potential (calculated by correcting for the decay of the first response) if it were identical to the first. Note that the facilitation was essentially absent in the control, increased with successive injections, and disappeared 10 min after the second injection, when the conditioned response amplitude was 2.5 times that of the control. No change in either the antidromic spike height or the resting membrane potential occurred (not shown).

directly compared. The left panel in $A$ consists of superimposed single- and paired-pulse recordings in the M-cell following a very low level of VIIIth-N stimulation. The right panel is a digital subtraction of the single response from the double, revealing the underlying amplitudes of the second electrical and chemical potentials. The apparent notches in the electrotonic potentials were due to the presence of an extracellular field; when the extracellular field was subtracted from the intracellular field, the net electrical potential resembled that of Figure 3 (not shown). In Figure $4 B$, one can see the dramatic effect of an injection of the cAMP-aminophylline mixture on the electrically and chemically mediated EPSP, the drugs having increased the responses by nearly 200 and $500 \%$, respectively, within $13 \mathrm{~min}$ of injection. There was no paired-pulse facilitation of the electrical EPSP in this experiment, but the facilitation of the chemically mediated EPSP was increased by cAMP, from 10 to $43 \%$. As indicated by the arrows in Figure $4 C$, the half-widths of both electrotonic potentials were unaffected by cAMP despite the large increases in electrical EPSP amplitudes. Out of 8 such experiments in which the electrotonic potentials were uncontaminated by stimulus artifacts or chemical EPSPs, allowing reliable measurements of their half-widths, this parameter actually decreased by an average of $4.50 \%(\mathrm{SD}=9.5)$, while the chemical EPSP amplitudes grew by $107.6 \%(S D=174.3)$ and the size of the electrical EPSPs increased by $44.6 \%(\mathrm{SD}=53.1)$. We conclude, therefore, that cAMP enhanced VIIIth-N excitatory responses via a mechanism different from that associated with the effects of cesium or 4-AP.

\section{Effects of cAMP on M-cell inhibitory responses}

In order to test whether cAMP could modify M-cell inhibitory responses, we postsynaptically injected cAMP into the M-cell while monitoring the IPSPs evoked by 2 different pathways, which are illustrated in Figure 5A. Activation of the M-cell recurrent collateral inhibitory network produces a powerful all- or-none IPSP due to synchronous excitation of about 80-100 inhibitory interneurons (Furukawa and Furshpan, 1963). In the second pathway, the inhibitory interneurons are activated through the contra- or ipsilateral VIIIth-N (Zottoli and Faber, 1980 ), with the IPSP amplitude being graded as a function of the stimulus strength. The processes of these interneurons terminate on the soma and proximal dendrite of the M-cell (Triller and Korn, 1982, 1986). Cyclic AMP was generally injected in the dendrite. In many instances, a second electrode was placed in the soma for cAMP or chloride injections, or for further monitoring inhibition.

An indirect method was used to assess the effects of cAMP on inhibitory synaptic conductances (Faber and Korn, 1982). Because the chloride equilibrium potential is very close to the resting potential in the $\mathrm{M}$-cell, inhibitory conductances do not produce clear potential changes when recordings are obtained using electrodes filled with solutions of potassium salts of impermeant anions such as acetate of sulfate. However, under these recording conditions, the inhibitory effects can be demonstrated by the shunt of an antidromic spike timed to occur at the peak of the underlying inhibitory postsynaptic conductance. The amplitude of this "conditioned" antidromic spike $\left(V_{s}^{\prime}\right)$ can then be compared with that of the control $\left(V_{s}\right)$, which is evoked in the absence of synaptic stimulation. The inhibitory responses and the effects of cAMP on them are, therefore, expressed in terms of the "percent inhibition," defined as the fractional reduction in antidromic spike height, $r$, multiplied by 100 (Faber and Korn, 1982), where

$$
r=\left(V_{s}-V_{s}^{\prime}\right) / V_{s}
$$

Inhibition can be estimated in this manner because the M-cell soma and lateral dendrite do not support active spike electrogenesis and are electrotonically separated from the spike-initiating zone (Furshpan and Furukawa, 1962; Diamond, 1968; Funch and Faber, 1982): The resting input conductance $\left(g_{m}\right)$ 
therefore does not change appreciably during an action potential. In fact, $r$ is only linearly related to $g_{i}$, the peak inhibitory synaptic conductance, when $g_{i} \ll g_{m}$, the more precise expression being

$$
g_{i}=[r /(1-r)] G_{m},
$$

where $G_{m}$ equals $g_{m}$ plus a series access conductance that couples the spike generator to the recording site. Therefore, Equation 2 tends to underestimate inhibition when it is large. Nevertheless, the data presented in this report are primarily expressed in terms of $r$, rather than $g_{i}$, because $G_{m}$ was not usually measured directly.

\section{Effects on VIIIth-N inhibition}

Cyclic AMP injections consistently produced an enhancement of the VIIIth-N inhibition, as shown in the example of Figure $5 B$. In this experiment, the preinjection inhibition was demonstrated by a $4 \%$ reduction (equivalent to $g_{i}=0.04 G_{m}$ ) in antidromic spike height (compare the upper and lower left panels). Within $10 \mathrm{~min}$ of an intradendritic cAMP injection, the magnitude of the inhibition had tripled to $12 \%\left(g_{i}=0.13 G_{m}\right)$. Note that the amplitude of the unconditioned spike did not change after injection, indicating that this enhancement was not due to changes in M-cell input conductance. Similar effects were found in 38 of 43 experiments. Furthermore, the cAMP effect was mimicked by aminophylline alone $(n=5)$.

The Mann-Whitney test was used to determine the statistical significance of the effects of cAMP-aminophylline on the VIIIth- $\mathrm{N}$ inhibition. In experiments in which more than one stimulus strength was used, the results from each strength were averaged together before the analysis. The test revealed that cAMP increased the level of inhibition by a median of 3.50 percentage points $(n=43)$, whereas vehicle injections $(n=13)$ reduced inhibition by 1.00 percentage point (preinjection levels of inhibition were $8.59 \%$ in the cAMP-aminophylline experiments and $10.7 \%$ in the controls). These values are statistically significant at the 0.0001 level. The cAMP effects appeared to be independent of whether the drug was injected into the ipsilateral or contralateral M-cell. As with excitation, the results obtained with 5'-AMP were statistically indistinguishable from those with vehicle, at the 0.0700 level. Adenosine 5'-monophosphate produced a median increase in inhibition of 0.53 percentage points, from an average preinjection level of $14.2 \%$.

Previous studies have shown that the IPSPs evoked by stimulation of either the VIIIth-N or the recurrent inhibitory pathway are chloride-dependent (Asada, 1963; Fukami et al., 1965). If the inhibition added by postsynaptic cAMP injections shares the same underlying mechanism, it should also be chloridedependent. To test this idea, we first iontophoresed chloride from a $\mathrm{KCl}$ electrode into the contralateral $\mathrm{M}$-cell (which receives no excitatory input from the VIIIth-N) until the chloride concentration reached a steady-state level; because this procedure changes the chloride equilibrium potential, chloride-dependent IPSPs manifested themselves as depolarizations. We then injected cAMP from a second electrode that did not contain chloride and measured changes in both the IPSP and the fractional reduction in spike amplitude. The results demonstrated that the cAMP-induced enhancement is, indeed, dependent upon chloride. An example of the evidence that supports this conclusion is shown in Figure 6. As illustrated in $A$, the control IPSP (left panel) was depolarizing, and superposed upon it was a test antidromic spike; the amplitude of the spike was measured
A

\section{CONTROL}
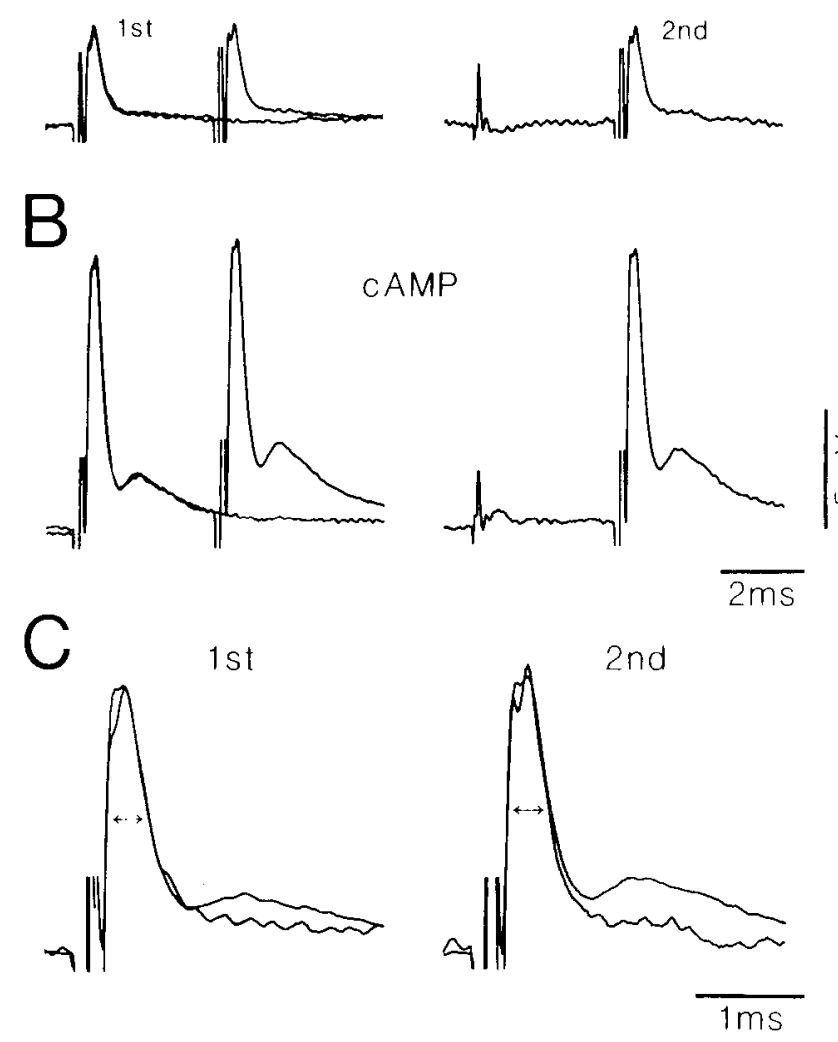

Figure 4. Chemical EPSP enhancement by cAMP occurred without any increase in the half-width of the electrical EPSP. $A$ and $B$, The effects of cAMP-aminophylline injection on VIIIth- $\mathrm{N}$ input to the M-cell. Left traces: Superimposed single- and paired-pulse sweeps demonstrate large cAMP effects on both the electrotonic potential and the chemical EPSP. Right traces: Digital subtraction of the traces at the left (double-pulse minus single-pulse) reveals the true amplitudes of the second EPSPs. $C$, Left traces: The first electrotonic potential in $A$ has been digitally scaled to match the height of that in $B$; the 2 were then expanded in time and superimposed. Right traces: Same manipulations used for the left traces, but for the subtracted second electrotonic potentials. No vertical calibrations are possible for this panel. Double arrows indicate the width at half-amplitude. Note that cAMP increased the amplitude of the chemical EPSP and induced its paired-pulse facilitation without changing the width of the electrotonic potential. All traces are averages of 10 or more sweeps. The labels $1 s t$ and $2 n d$ refer to the first and second electronic potentials, respectively.

from its point of departure from this IPSP (arrows). This method of measuring spike height has been found to be more reliable than measuring from the baseline in cells in which we quantified the inhibition while varying the degree of chloride-loading. For comparison, the unconditioned antidromic spikes are shown in Figure $6 B$; they are followed by long-lasting depolarizations, which are collateral IPSPs. Contrasting the control data with those collected within $8 \mathrm{~min}$ of injection (right panels), it can be seen that cAMP increased the amplitude of the chloridedependent VIIIth-N IPSP by a factor of about 3 , while increasing the shunt of the antidromic spike from 14 to $37 \%$. Finally, cAMP also augmented the collateral IPSP. In this particular experiment, the unconditioned spike dropped $8 \%$ after injection, but this slight reduction in input resistance is of the wrong polarity to account for the dramatic effect on inhibitory conductance ( $\mathrm{scc}$ below). 

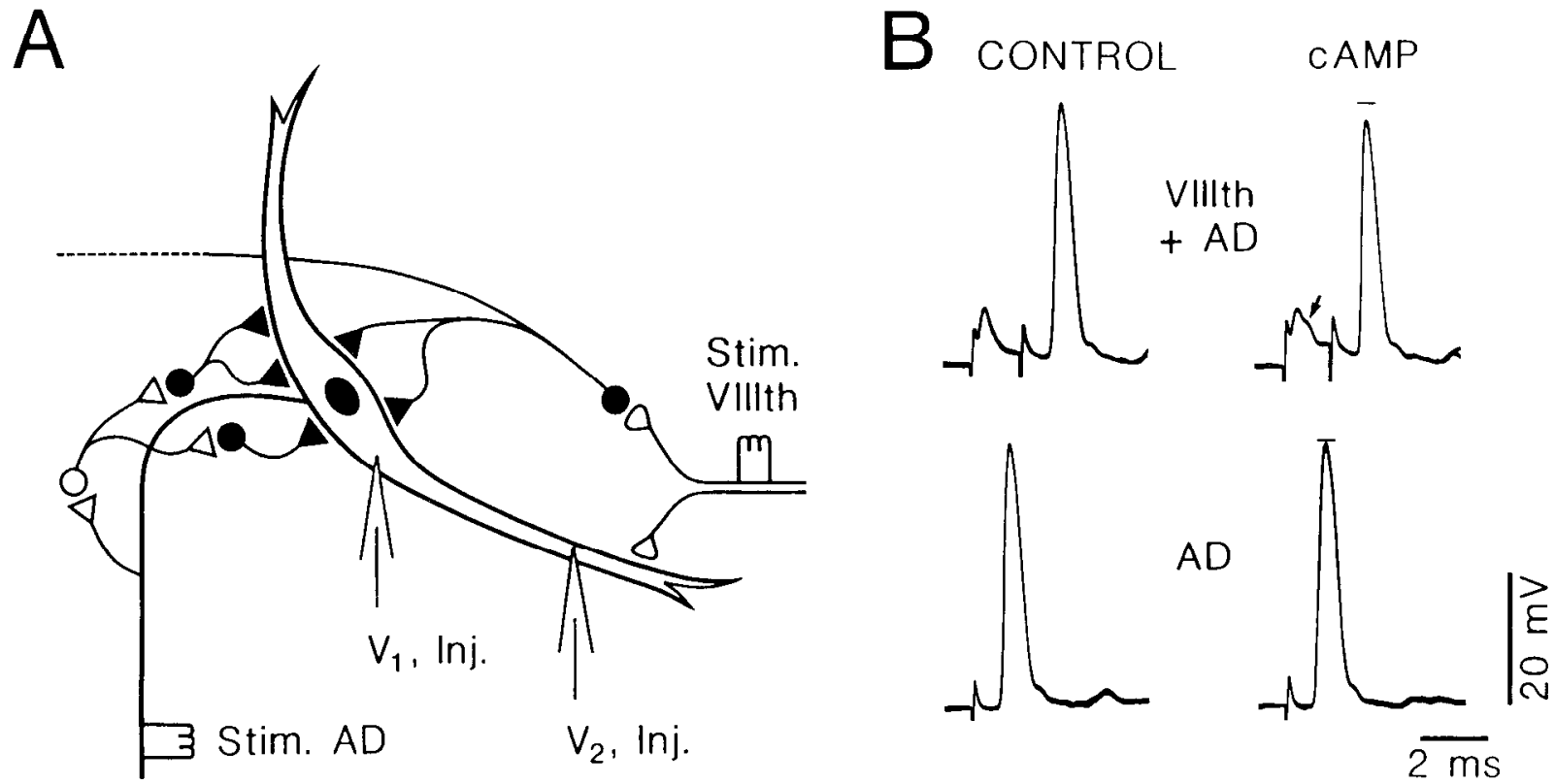

Figure 5. Cyclic AMP-enhanced M-cell inhibitory responses. A, Schematic diagram, illustrating 2 of the M-cell's inhibitory networks. Antidromic $(A D)$ stimulation of the M-cell activates a powerful collateral network, while stimulation of the VIIIth-N activates a weaker pathway, which can be graded. Simultaneous intrasomatic and intradendritic recordings were performed to permit the comparison of the effects of iontophoresis at 2 loci and to facilitate the process of chloride loading, when utilized. The dashed line denotes a branch of a commissural inhibitory interneuron (or "PHP cell") crossing the midline, after which it synapses on the contralateral M-cell (not shown). B, Effect of cAMP on VIIIth-N inhibition. These intradendritic recordings demonstrate the $\mathrm{M}$-cell response to subthreshold stimulation of the ipsilateral VIIIth-N, followed by an antidromically evoked action potential (upper traces). The reduction in amplitude of this antidromic spike relative to one which is not conditioned by VIIIth-N stimulation (lower traces) is an index of the inhibitory conductance associated with that particular VIIIth-N stimulus strength. The upper-right record shows that cAMP increased the VIIIth-N-evoked inhibitory conductance (the bar indicates the preinjection level of inhibition). Note that the chemical EPSP of the excitatory VIIIth-N input was also augmented (arrow) and that the test antidromic spike amplitude was unchanged (lower traces).

Figure 6. cAMP-induced inhibition was chloride-dependent. $A$ and $B$, In this experiment, the somatic electrode was used to iontophoretically load the contralateral M-cell with chloride, thereby unmasking IPSPs as depolarizations. Responses are shown before (left) and after (right) intradendritic injections of cAMP. A, Cyclic AMP increased the level of VIIIth-N-evoked inhibition to a value well above that in the control, as indicated not only by the reduction in antidromic spike height, but also by the increase in the magnitude of the depolarizing IPSP (arrows). The collateral inhibition, following the antidromic spike, was also augmented such that the depolarizing IPSP actually fired the cell a second time. $B$, Unconditioned antidromic spike amplitude dropped slightly after cAMP, but this cannot account for the increase in inhibition seen in $A$. Note again the augmentation of the collateral IPSP following the antidromic spike. Dashed lines indicate the baseline. All traces are averages of 10 sweeps.

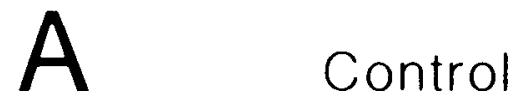

CAMP
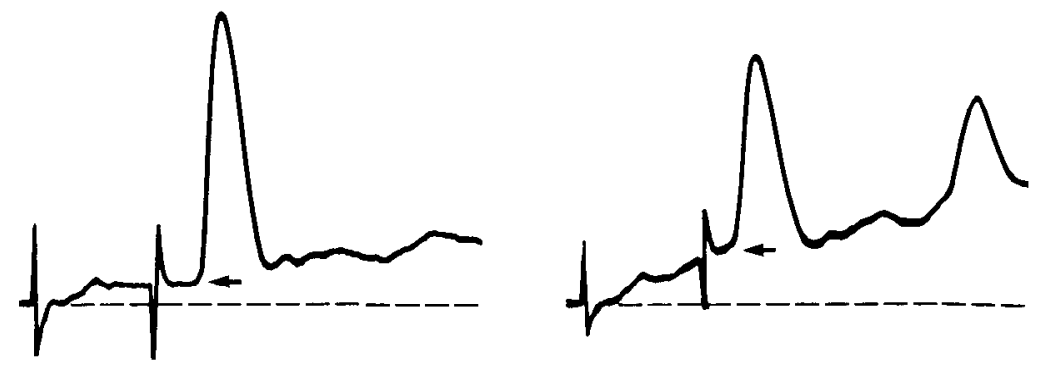

B

Control

cAMP
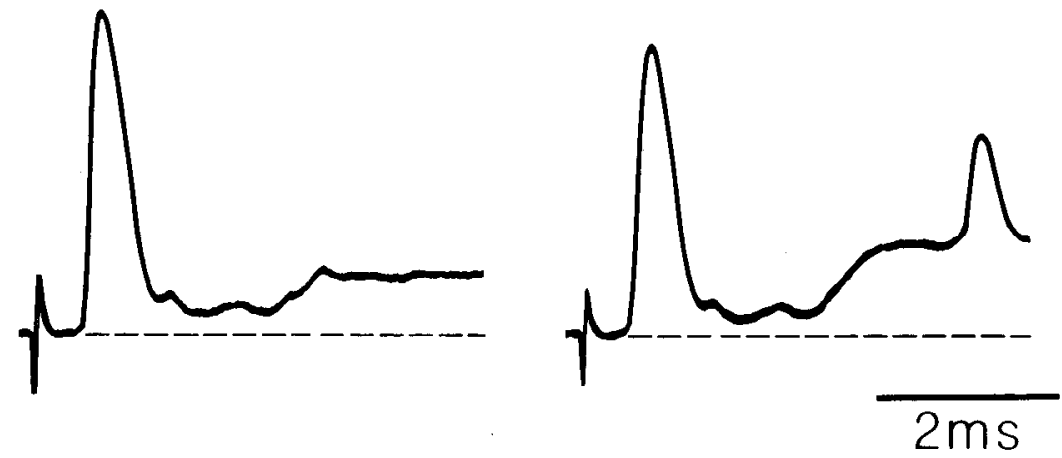


\section{$A D+A D$}

\section{CONTROL}
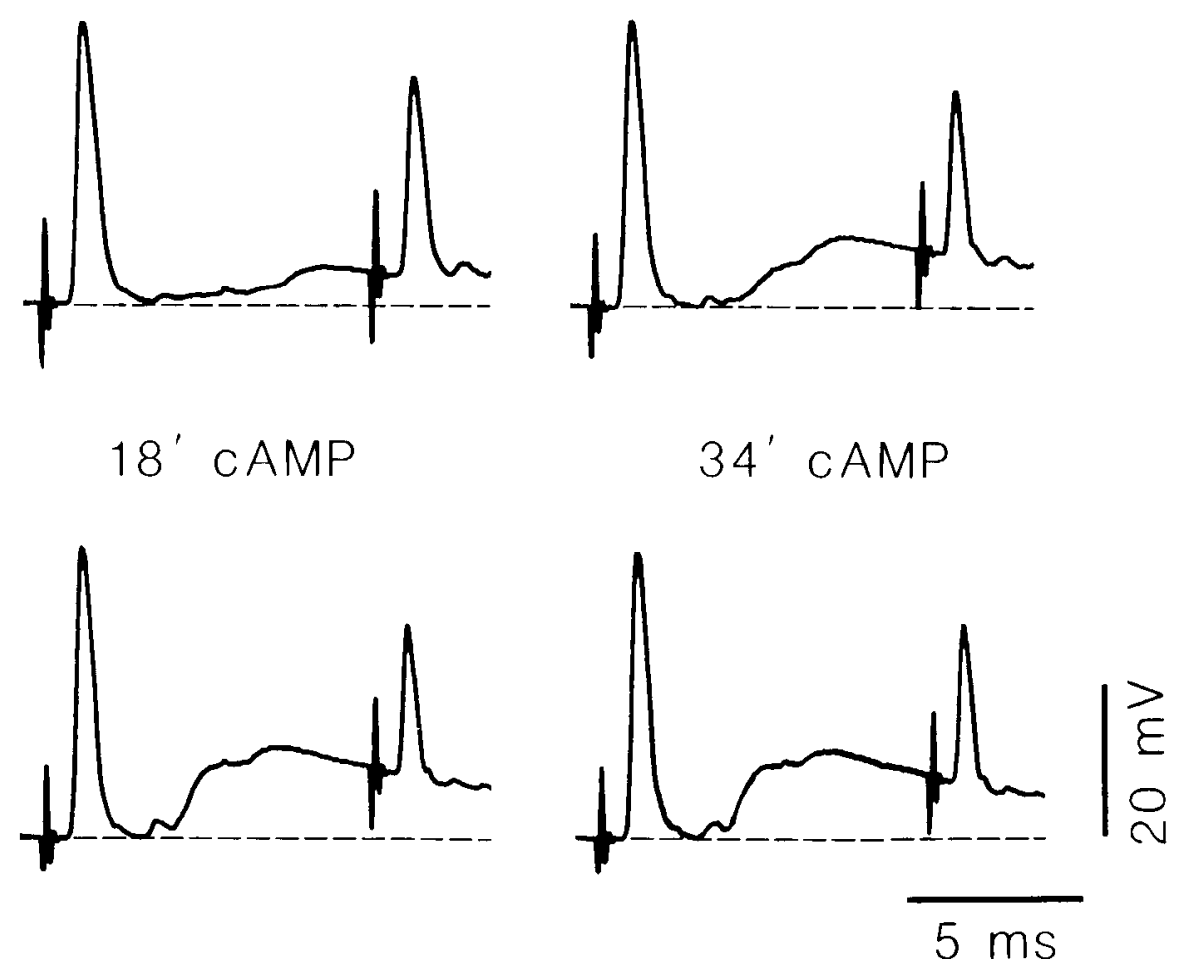

Figure 7. In this experiment, we used paired antidromic stimuli in a chlorideloaded cell to demonstrate the effect of cAMP-aminophylline on collateral inhibition. The first stimulus activates the collateral IPSP, which shunts the second spike. As can be seen from the reduction in amplitude of the second action potential and from the growth of the collateral IPSP, cAMP augmented the collateral inhibitory conductance, an effect that increased with time until it plateaued at $34 \mathrm{~min}$. Note that the amplitude of the first spike was unchanged, indirectly indicating constant input resistance. Membrane potential did not vary (not shown). All traces are averages of 10 or more sweeps.

\section{Collateral inhibition}

The 2 types of interneurons that mediate the VIIIth-N and collateral inhibitions have similar physiological properties, although they are morphologically distinct (Triller and Korn, 1982, 1986). The increase in the amplitude of the collateral IPSP in experiments such as that above suggested that cAMP enhanced the inhibition produced by the collateral network as well as that by the VIIIth-N. To further quantify this effect, cAMP was injected into a chloride-loaded M-cell while the IPSP amplitude was monitored, and the magnitude of the collateral inhibitory conductance was measured from the reduction in amplitude of a test spike (the second of a pair) (Fukami et al., 1965). We found that CAMP produced the expected enhancement of the collateral IPSP and increased the value of the percent inhibition as well. Figure 7 illustrates results of such an experiment, including some details of the time course of the cAMP effects. The baseline level of inhibition is evident in the control as either a $5.2 \mathrm{mV}$ depolarizing IPSP or as a $29 \%$ reduction in amplitude of the second spike. Five minutes after injection of cAMPaminophylline, the IPSP had nearly doubled and the inhibitory shunt increased to $42 \%$. These effects were even more pronounced at $18 \mathrm{~min}$, but no further changes occurred at longer time intervals (compare 18 and 34 min postinjection). The amplitude of the unconditioned antidromic spike remained constant throughout the experiment. As with the other effects described here, injections of aminophylline $(n=5)$ produced changes in the collateral inhibition comparable to the effects of cAMP alone or of the 2 together. These observations indicate once again that this second messenger is endogenous to the M-cell.

The Mann-Whitney test was applied to the data from the experiments involving the collateral inhibition. Healthy cells were defined in this case as being those that not only retained at least $85 \%$ of their original spike amplitude, but also those that had at least $20 \%$ inhibition before injection, as this value indicates the minimum level of inhibition that is normally observed in healthy cells (Faber and Korn, 1982). The median increase in inhibition following cAMP-aminophylline injection was 3.00 percentage points $(n=34)$, whereas control injections produced a median decrease of 1.50 percentage points $(n=10)$. These values are significant at the 0.0269 level. The average inhibition before injection was $48.8 \%$ in the cAMP-aminophylline experiments and $51.5 \%$ in the controls. When $5^{\prime}$-AMP was injected $(n=9)$, the median increase in collateral inhibition was 0.12 percentage points, from an average of $43.2 \%$. This negligible effect was statistically indistinguishable from those obtaincd with vehicle injections, at the 0.2045 level. One should note that although the cAMP-induced increases in collateral inhibition at first seem small in comparison with the original inhibition, the activation of the collateral network normally produces a very large inhibitory conductance, which, due to nonlinear summation (Faber and Korn, 1982), creates a disproportionate relationship between the fractional reduction in spike height and the magnitude of the inhibitory conductance. The true values of the additional $g_{i}$ contributed by cAMP are therefore larger than revealed by this calculation (see Discussion). 
A

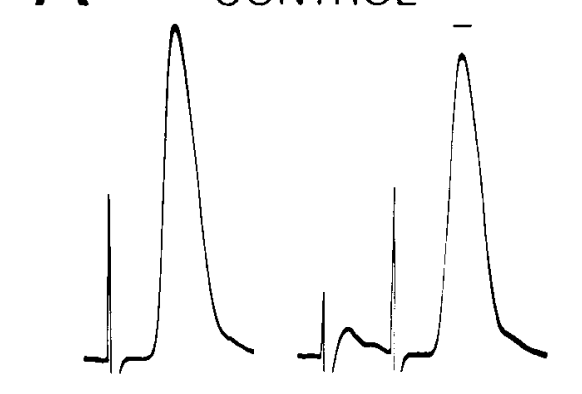

CONTROL

B CONTROL

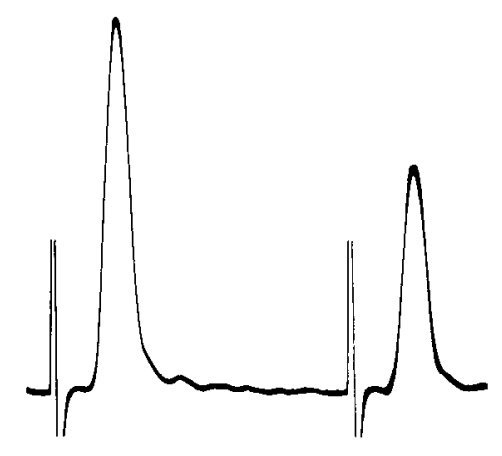

CAMP

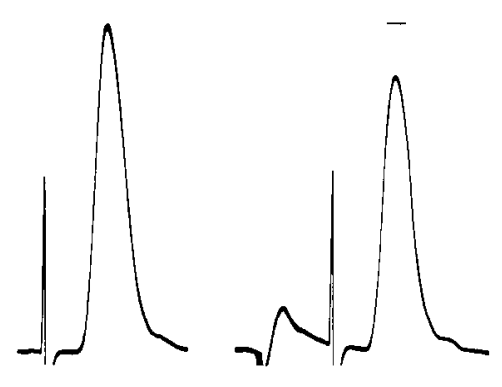

CAMP

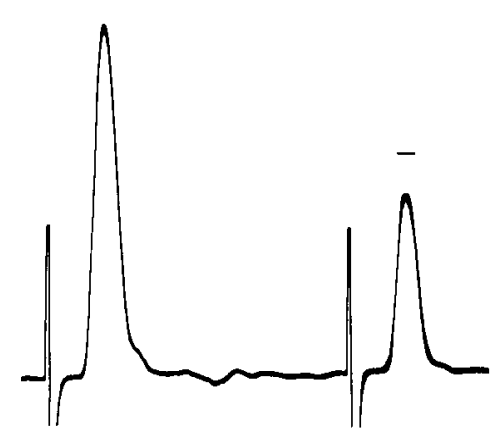

STRYCHNINE
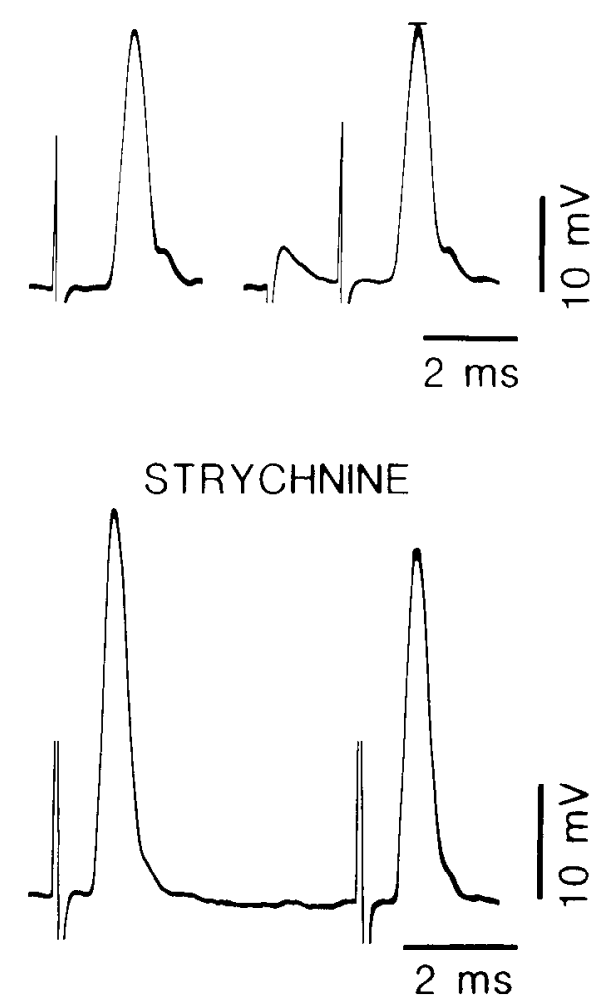

Figure 8. Cyclic AMP-induced conductances were strychnine-sensitive. A, Cyclic AMP nearly doubled the amplitude of VIIIth-N inhibition, but iontophoresis of strychnine into the axon cap abolished it completely. Bars indicate the amplitude of the unconditioned antidromic spike, which is itself shown in the left of each pair of recordings. $B$, Cyclic AMP increased collateral inhibition, after which strychnine iontophoresis extinguished it. The amplitude of the first antidromic spike remained unchanged. $B a r$ denotes the control level of inhibition. The data in $A$ and $B$ are from 2 different cells. The data shown are single sweeps but have been selected to represent the averages of at least 7 such traces.

\section{Strychnine sensitivity of cAMP-induced inhibitions}

The cAMP-enhanced inhibitions were antagonized by strychnine, which is an antagonist of glycine, the putative inhibitory transmitter at these synapses (Furukawa et al., 1964; Diamond et al., 1973; Mazliah and Werman, 1974; see Faber and Korn, 1978). Figure 8 illustrates results from 2 experiments similar to those described above, in which the VIIIth-N $(A)$ and the collateral $(B)$ inhibitory conductances were augmented by cAMP 13 and 2 min postinjection, respectively. Strychnine was subsequently iontophoresed into the region of the axon cap, where the majority of the inhibitory terminals are located (Triller and Korn, 1982, 1986). Figure $8 A$ shows that strychnine not only antagonized the inhibition induced by cAMP but, as expected, also eliminated that which was present in the control. In this case, the strychninc injection damaged the cell somewhat in that the unconditioned antidromic spike amplitude dropped from its control value, but this effect cannot account for the abolition of the inhibition. The data in Figure $8 B$ demonstrate that strychnine also eliminated the collateral inhibition completely: the slight reduction in test spike amplitude that remained after the drug was due to refractoriness of the Mauthner axon, as determined by the persistence of the reduction during highfrequency stimulation (not shown). Note that in the experiment of Figure $8 B$, the amplitude of the unconditioned antidromic spike was unaffected by strychnine iontophoresis.

\section{Controls}

Figure 9 demonstrates that the cAMP effects on VIIIth-N inhibition were not artifacts of injection. The controls in $A$ and $B$ are from 2 experiments in which the VIIIth-N stimulus strength was adjusted such that no inhibition was apparent before injection. In the example of Figure 9A, cAMP surprisingly unmasked or induced an inhibitory conductance which produced an $11 \%$ inhibition. In contrast (Fig. $9 B$ ), the injection of vehicle alone produced no inhibitory conductance. Similar negative results were obtained with vehicle injections in 8 out of $10 \mathrm{ex}$ periments involving the collateral inhibition and in all experiments involving the VIIIth-N inhibition $(n=13)$; that is, the vehicle neither induced nor enhanced an inhibitory conductance. This observation was consistent, regardless of the identity of the vehicle, the length of injection, or the time clapsed after injection.

\section{General characteristics of cAMP effects}

Because the monosynaptic excitatory input from the VIIIth-N is confined to the distal lateral dendrite while the inhibitory input is localized to the cell body (Lin et al., 1983; Triller and Korn, 1982, 1986), we attempted to determine how the site of injection (soma vs. dendrite) affected the magnitude of the cAMP effects. The injection location was found to influence the development of the effects on excitation more than those on in- 

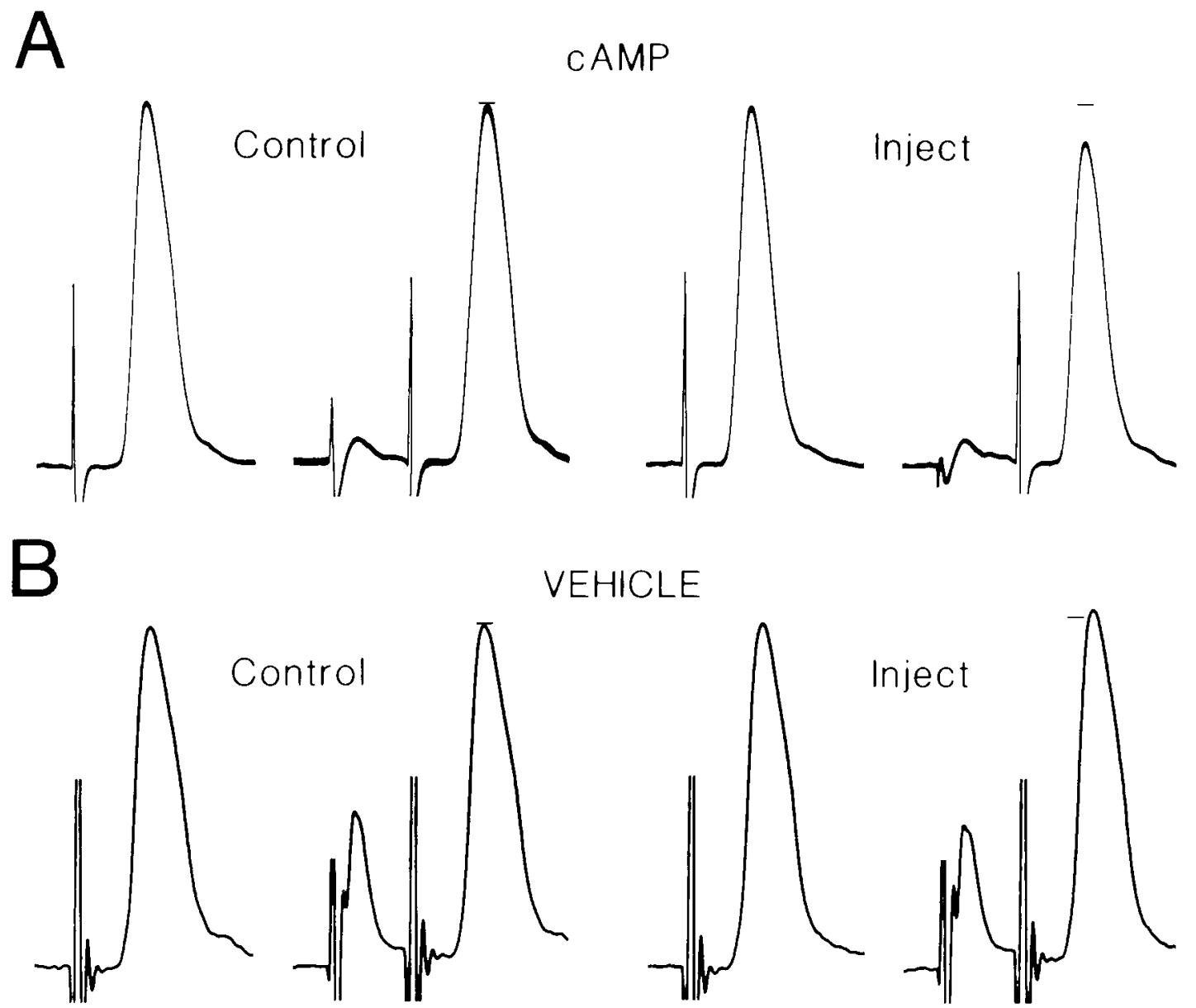

VEHICLE

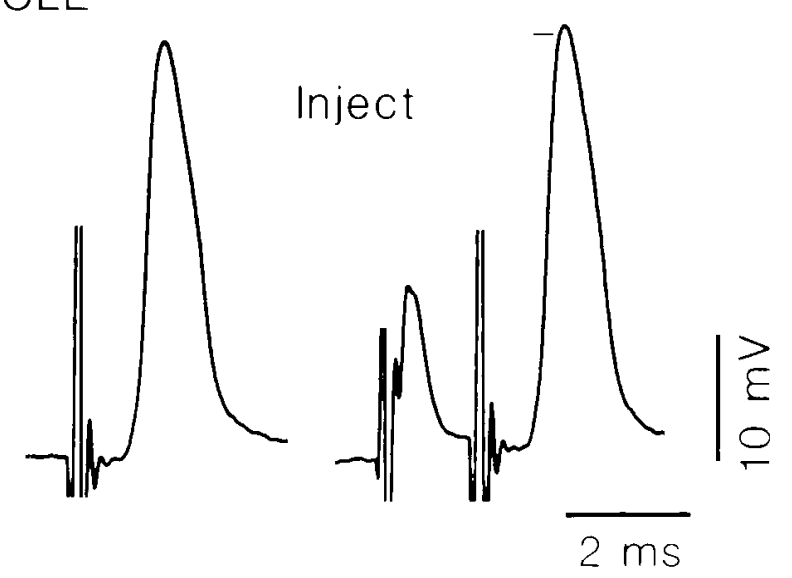

Figure 9. Cyclic AMP effects on VIIIth-N inhibition were not artifacts of injection. $A$, Cyclic AMP unmasked a large inhibitory conductance where there previously was none. Individual curves represent data averages. $B$, Injection of vehicle had no effect on inhibition. Traces are averages of 10 sweeps. Bars indicate amplitudes of unconditioned antidromic spikes.

hibition. Inhibitory responses were enhanced within roughly the same time period whether the injection was in the soma or the dendrite; the excitatory responses, however, appeared somewhat later when cAMP was iontophoresed into the soma. Given the higher rate of diffusion from a restricted space to one more voluminous (i.e., from the dendrite to the soma) than in the reverse situation, this is not a surprising finding.

In nearly every experiment, the effects of cAMP-aminophylline injection became manifest almost immediately after the termination of (the 3-5 min) iontophoresis; the time of onset could not be defined more specifically, however, because cAMP apparently began to act within the period of injection. These effects generally reached their plateau by $10 \mathrm{~min}$ postinjection, although in some experiments the enhancements continued to increase for up to $20 \mathrm{~min}$. Reversal of the responses was never observed with any drug solution within the maximum recording time (up to $3 \mathrm{hr}$ ) of the experiment.

Multiple cAMP injections produced variable results: for those experiments in which no effect was observed after one injection, a second would often induce enhancement. However, when the first injection did show positive effects, a second might or might not augment the responses further, indicating that there may be a ceiling to the cell's responsiveness to cAMP. Alternatively, this variability may have been the result of the preinjection level of cAMP in the cell or of the quality of injection; regardless, it made the determination of a dose-response curve impossible.

Aminophylline was a much more potent potentiator of cAMP effects than its hydrophobic counterpart, isobutylmethylxanthine. This difference in effectiveness is presumably due to the hydrophilic nature of aminophylline, which increases its likelihood of remaining within the aqueous environment of the cytoplasm.

\section{Discussion}

The major effects described in this report following postsynaptic injection of cAMP are (1) an increase in the electrically mediated EPSP of club ending synapses, (2) an increase in the chemically mediated EPSP from the same endings and (3) an enhancement of inhibitory conductances, following both ipsi- and contralateral VIIIth-N stimulation and antidromic stimulation, at synapses presumably localized to the soma and proximal dendrites. As will be described below, we suggest that the electrical potential was enhanced by increasing gap junctional conductance (from either side of the synapse), the chemical EPSP was increased via either a pre- or postsynaptic mechanism, and the IPSP was augmented through a postsynaptic process. However, bcfore discussing these mechanisms, it is necessary to consider whether any or all of these phenomena were due to nonspecific 
changes in either membrane properties or the intracellular environment.

\section{Possible nonspecific cAMP effects}

Given that the injecting electrode was no more than $150 \mu \mathrm{m}$ from the synapses in question, it must first be established that there was ample time for the drug to diffuse to the sites of action and exert its effects within the 3-5 min period of injection. Calculations of the average distance that a molecule of cAMP would diffuse in a given amount of time indicate that this time frame is adequate. The diffusion coefficient $(D)$ of cAMP in water at $21^{\circ} \mathrm{C}$ is $4 \times 10^{-6} \mathrm{~cm}^{2} / \mathrm{sec}$ (Cohen et al., 1975), suggesting that a molecule of cAMP would travel an average of 150 $\mu \mathrm{m}$ within $28 \mathrm{sec}$, based on the 1 -dimensional model of diffusion appropriate for an approximately linear dendrite (Einstein, 1956):

$$
\text { distance }^{2}=2 D \times \text { time. }
$$

Furthermore, because there is a continuous resupply of cAMP at the source throughout the period of injection, the effective distance increases significantly. The value of the diffusion coefficient could be reduced by as much as a factor of 7 , due, for example, to the added viscosity of the cytoplasm, and still allow cAMP ample time to reach its targets within $3 \mathrm{~min}$.

Transient decreases in intracellular $\mathrm{pH}$ associated with cAMP hydrolysis by phosphodiesterase are probably not responsible for any of the observed enhancements. Such $\mathrm{pH}$-induced changes are rendered unlikely by (1) the similar effects of aminophylline, which inhibits cAMP hydrolysis; (2) the presumed large hydrogen ion-buffering capacity of a neuron the size of the M-cell; and (3) the persistence of the cAMP effects. Furthermore, reduced $\mathrm{pH}$ decreases, rather than enhances, gap junctional conductance in both neuronal and non-neuronal cell systems (see Spray and Bennett, 1985, for review). Similarly, any elevation of the intraterminal calcium concentration that may have been induced by cAMP would presumably have reduced the amplitude of the electrotonic potential (Rose and Loewenstein, 1970, 1975; Obaid et al., 1983).

It is conceivable that increases in both types of EPSPs and in inhibitory conductance could be due to a decrease in M-cell input conductance or to nonlinear responses to depolarization, such as those produced by a rectifier (Faber and Korn, 1986). The first possibility was not the case, however, as indicated by the constancy of the unconditioned antidromic spike amplitudes and by the data from 2-electrode experiments in which the $\mathrm{M}$-cell resting input resistance (or, more appropriately, transfer resistance) was directly measured before and after cAMP injection. With reference to the second possibility, (1) most of the excitatory responses studied were very small and were therefore unlikely to have involved any nonlinear membrane properties, and (2) the cAMP effects appeared to be independent of preinjection response amplitudes.

The effects reported here were produced by injections of cAMP, alone or in combination with aminophylline, and by aminophylline alone. Since aminophylline prevents breakdown of cAMP by the phosphodiesterase, these results suggest that the effects were not due to a nonspecific action of the breakdown products, which are $5^{\prime}$-AMP and hydrogen ions. This conclusion was supported by the injection of 5 '-AMP into the M-cell in the same concentration as was used for cAMP, finding that 5'AMP had no effect. Therefore, nonspecific effects cannot explain the observed actions of cAMP.

\section{Cyclic AMP effects on excitation}

The analysis of the effects of cAMP on excitation is complicated by the fact that the involved synapses are morphologically mixed, thus potentially allowing molecules the size of cAMP to diffuse across the gap junctions. Therefore, cAMP could exert its effects from either the pre- or postsynaptic side of the junction.

The enhancement of the electrically mediated EPSP by cAMP is most likely due to an increase in the gap junctional conductance, probably via the modification of junctional proteins (Saez et al., 1986). As only about $2 \%$ of the gap junctional channels in individual large, myelinated club endings are functionally conducting (Lin and Faber, 1988a), cAMP may play a role in regulating the number of functional channels or in the modifcation of single-channel properties, or both. An alternative possibility is that cAMP may instead have increased presynaptic spike amplitudes. However, in other systems, cAMP effects on presynaptic voltage-dependent conductances are associated with concomitant changes in the time course of the presynaptic spike (Castellucci et al., 1980; Schuster et al., 1985). This appears not to be the case in our experiments because the waveform of the electrotonic potential, which is indicative of that of the saccular fiber action potential (Lin and Faber, 1988a, b), was not changed by cAMP.

The increase in amplitude of the chemically mediated EPSP may have occurred postsynaptically via a change in the number or sensitivity of postsynaptic receptors or channels, or presynaptically, through an enhancement of transmitter release. If the latter were true, the increase in release would have had to occur in the absence of presynaptic spike-broadening, perhaps involving a "third" messenger such as intracellular calcium (Katz and Miledi, 1968; Miledi and Thies, 1971; Charlton et al., 1982; Zucker and Lara-Estrella, 1983; Zucker and Stockbridge, 1983). Resolution of this pre- versus postsynaptic issue requires (1) prior uncoupling of the gap junctions or (2) injection of the catalytic subunit of the cAMP-dependent protein kinase, which is too large to cross gap junctions; if the kinase were unable to enhance the chemical EPSP, it would support the notion that cAMP had crossed the gaps and exerted its effects there. This issue is important not only for the delineation of the involved molecular mechanisms, but also because it may shed some light on the physiological role of neuronal electrotonic junctions. In a neuron such as the $\mathrm{M}$-cell, in which the VIIIth-N electrotonic potential is often of sufficient amplitude to fire the cell, the additional ability of the gap junctions to exchange metabolites that exert different effects on each side of the membrane would endow the junctions with tremendous potential for the regulation of synaptic plasticity at these and, perhaps, at other cellular loci (Bennett, 1977; Faber et al., 1980; Spray and Bennett, 1985).

Although the cAMP-enhanced paired-pulse facilitations of the electrical and chemical EPSPs were often dramatic (e.g., Fig. 3), we did not evaluate these effects statistically because the VIIIth-N IPSP has a latency and duration that coincides with the second of the paired excitatory responses, and, as shown in this report, this IPSP is also affected by cAMP. Nevertheless, facilitation did increase a number of times even when the IPSP was itself enhanced. Thus, the effects of cAMP on these facilitations were, therefore, probably underestimated. The interpretation of these results is complicated by the fact that the mechanism underlying the preinjection paired-pulse facilitation of electrotonic potentials is unclear. Two possibilities include nonlinear membrane or junctional properties and recruitment of 
saccular fibers not brought to threshold by the first stimulus. Such mechanisms might also contribute to the paired-pulse facilitation of the chemical EPSPs, in conjunction with the facilitated release that has been shown to occur from single fibers (Lin and Faber, 1988b).

\section{Cyclic AMP effects on inhibition}

The effects of cAMP on inhibitory responses of the M-cell were quite dramatic. Specifically, the cAMP-induced increase in VIIIth-N inhibition of 3.50 percentage points from a baseline value of $8.59 \%$ inhibition translates to a $41 \%$ increase in inhibition. Although the 3.00 percentage point increase in the collateral inhibition from $48.8 \%$ appears to be small, it actually represents a larger change in the collateral inhibitory conductance because, as mentioned earlier, the large size of this inhibition causes increments in inhibitory conductance to add nonlinearly. Therefore, $g_{i} / G_{m}$ (Equation 3$)$ is a closer estimate of inhibitory conductance, for it corrects for this nonlinearity. Using the above relationship, the VIIIth- $\mathrm{N}$ inhibitory conductance increased from $g_{i}=0.09 G_{m}$ to $g_{i}=0.14 G_{m}$ (up 56\%), while the collateral IPSP increased from $g_{i}=0.95 G_{m}$ to $g_{i}=1.07 G_{m}$ (up $13 \%)$.

The large difference in the effect on these 2 types of inhibition raises the question of why $\mathrm{M}$-cell responses to members of the same general class of inhibitory interneurons are altered by cAMP to different degrees. One possibility is that the subset of synapses activated via the VIIIth-N are simply more susceptible to modification by second messengers. Alternatively, the collateral response, which involves activation of a large number of such cells, may already possess some nonlinear properties, such as those which might occur with the spread of glycine to adjacent synapses (Faber and Korn, 1988).

In contrast to the ambiguity concerning the locus of the cAMP effects on the excitatory responses, it is most likely that the enhanced inhibition results from a postsynaptic mechanism. There is no obvious pathway by which cAMP could directly change inhibitory transmitter release at the inhibitory synapses because it is membrane impermeable and because there are no gap junctions between the inhibitory interneurons and the M-cell (Triller and Korn, 1982). Similarly, a number of arguments can be raised against the notion that cAMP enhanced inhibition by diffusing across the gap junctions which couple the $\mathrm{M}$-cell to the excitatory fibers, and subsequently altering the level of excitation of the VIIIth-N inhibitory interneurons; this might occur by changing the excitability of those excitatory fibers that send branches to the inhibitory interneurons, thereby increasing the number of the latter activated by a given stimulus. First, recruitment of these neurons by VIIIth-N fibers would not explain the enhanced collateral inhibition. Second, in some experiments we monitored the extrinsic hyperpolarizing potential in the M-cell's axon cap. This potential, which is proportional to the presynaptic inhibitory volley (Furukawa and Furshpan, 1963; Faber and Korn, 1978), was unchanged after cAMP injections, for either type of inhibitory connection. Third, cAMP diffusion and subsequent recruitment of inhibitory interneurons cannot occur when cAMP is injected into the contralateral Mcell, and we found there to be no difference in the cAMP effects on inhibition between the 2 cells. Although it is possible that cAMP triggers the release of some diffusible substance that alters presynaptic release parameters, it is more likely that cAMP increases the number of functional glycine receptors or alters chloride channel properties. One approach that could be used to distinguish between these possible mechanisms would be to apply the quantal analysis previously used at these synapses by Korn and colleagues $(1982,1987)$. These analyses predict that, if the cAMP effects were postsynaptic, the release parameters, $n$ and $p$, would be unchanged, while the quantal size, $q$, would be increased by an amount proportional to the change in $g_{i}$. In either case, the data in this report provide one of the few examples of modulation of glycinergic responses (see also Werman and Mazliah, 1978).

In 7 experiments, cAMP increased the VIIIth- $\mathrm{N}$ inhibitory conductance from zero to a large value (e.g., Fig. 9), inducing IPSPs equivalent to those produced by the activation of 1-5 average inhibitory interneurons (Faber and Korn, 1982). It is possible that the absence of a detectable inhibition in controls may have been related to the limits of signal resolution. Regardless, these results suggest that cAMP may have unmasked a large number of functionally silent synaptic connections, perhaps by recruiting dormant patches or clusters of receptor-channel complexes.

\section{Functional consequences}

The ability of cAMP and aminophylline to modulate the $M$-cell responses described here implies that this neuron possesses endogenous mechanisms by which it modulates excitation and inhibition. The fact that one second messenger increases the gain of both types of responses raises the question of how the cell controls local concentrations of effector and what the triggers for such modulations might be. Candidates for the latter might include transmitters such as dopamine or 5-H'I or peptide cotransmitters. In this context, it might be significant that neurons and fibers containing monoamincs are found in the goldfish brain stem in regions near the M-cell (Bonn, 1987; Korn et al., unpublished observations). Equally intriguing are the presumed functional consequences of these changes in M-cell excitability. Orthodromic activation of the M-cell initiates an escape behavior known as the "startle response" (Yasargil and Diamond, 1968; Zottoli, 1977; Eaton et al., 1981; Eaton and Hackett, 1984; Zottoli et al., 1987). Previous studies have demonstrated that the startle behavior habituates (Aljure et al., 1980); it therefore displays a degree of plasticity even though the survival of the animal may depend, to a great extent, upon the reproducibility and reliability of its output. Thus, selective increases in inhibition or excitation via the mechanisms described here might lead to suppression of the reflex or to behavioral sensitization, respectively. These 2 processes would presumably be subjected to differential regulation, based on the trigger signals and the spatial segregation of the excitatory and inhibitory inputs. $\mathrm{Al}$ though the experiments described in this paper do not directly address behavioral issues, their results suggest that the M-cell system may be an ideal candidate for such investigations.

\section{References}

Aljure, E., J. W. Day, and M. V. L. Bennett (1980) Postsynaptic depression of Mauthner Cell-mediated startle reflex, a possible contributor to habituation. Brain Res. 188: 261-268.

Asada, Y. (1963) Effects of intracellularly injected anions on the Mauthner Cells of goldfish. Jpn. J. Physiol. 13: 583-598.

Bennett, M. V. L. (1977) Electrical transmission: A functional analysis and comparison to chemical transmission. Handbook of Physiology, Section I: The Nervous System, I (1): 357-416.

Bonn, U. (1987) Distribution of monoamine-containing neurons in the brain of a teleost, Carassius auratus (Cyprinidae). J. Hirnforsch. 28: $529-544$ 
Bormann, J. (1988) Electrophysiology of $\mathrm{GABA}_{\mathrm{A}}$ and $\mathrm{GABA}_{B}$ receptor subtypes. TINS 11: 112-116.

Browning, M. D., R. Huganir, and P. Greengard (1985) Protein phosphorylation and neuronal function. J. Neurochem. 45: 11-23.

Castellucci, V. F., E. R. Kandel, J. H. Schwartz, F. D. Wilson, A. C. Nairn, and P. Greengard (1980) Intracellular injection of catalytic subunit of cyclic AMP-dependent protein kinase simulates facilitation of transmitter release underlying behavioral sensitization in Aplysia. Proc. Natl. Acad. Sci. USA 77: 7492-7496.

Charlton, M. P., S. J. Smith, and R. S. Zucker (1982) Role of presynaptic calcium ions and channels in synaptic facilitation and depression at the squid giant synapse. J. Physiol. (Lond.) 323: 173-193.

Cohen, M. H., D. Drage, and A. Robertson (1975) Iontophoresis of cyclic AMP. Biophys. J. 15: 753-763.

Diamond, J. (1968) The activation and distribution of GABA and L-glutamate receptors on goldfish Mauthner neurons: An analysis of dendritic remote inhibition. J. Physiol. (Lond.) 158: 296-323.

Diamond, J., S. Roper, and G. Yasargil (1973) The membrane effects and sensitivity of strychnine, of neural inhibition of the Mauthner Cell, and its inhibition by glycine and GABA. J. Physiol. (Lond.) 232: 87-111.

Eaton, R. C., and J. T. Hackett (1984) The role of the Mauthner Cell in fast-starts involving escape in teleost fishes. In Neural Mechanisms of Startle Behavior, R. C. Eaton, ed., pp. 213-266, Plenum, New York.

Eaton, R. C., W. A. Lavender, and C. M. Wieland (1981) Identification of Mauthner-initiated response patterns in goldfish: Evidence from simultaneous cinematography and electrophysiology. J. Comp. Physiol. 144: 521-531.

Einstein, A. (1956) Investigations on the theory of the Brownian movement. As reprinted in Investigations on the Theory of the Brownian Movement, R. Furth, ed., pp. 1-17, Dover, New York.

Faber, D. S., and H. Korn (1978) Electrophysiology of the Mauthner cell: Basic properties, synaptic mechanisms, and associated network. In Neurobiology of the Mauthner Cell, D. S. Faber and H. Korn, eds., pp. 47-132, Raven, New York.

Faber, D. S., and H. Korn (1982) Transmission at a central inhibitory synapse. I. Magnitude of unitary postsynaptic conductance change and kinetics of channel activation. J. Neurophysiol. 48: 654-678.

Faber, D. S., and H. Korn (1986) Instantaneous inward rectification in the Mauthner Cell: A postsynaptic booster for excitatory inputs. Neuroscience 9: 1037-1043.

Faber, D. S., and H. Korn (1988) Synergism at central synapses due to lateral diffusion of transmitter. Proc. Natl. Acad. Sci. USA 85: 8708-8712.

Faber, D. S., C. Kaars, and S. J. Zottoli (1980) Dual transmision at morphologically mixed synapses: Evidence from postsynaptic cobalt injections. Neuroscience 5: 433-440.

Flagg-Newton, J. (1980) The permeability of the cell-to-cell membrane channel and its regulation in mammalian cell junction. In Vitro 16: 1043-1048.

Flagg-Newton, J., I. Simpson, and W. R. Loewenstein (1979) Permcability of the cell-cell membrane channcls in mammalian cell junction. Science 205: 404-409.

Fukami, Y., T. Furukawa, and Y. Asada (1965) Excitability changes of the Mauthner Cell during collateral inhibition. J. Gen. Physiol. 48: 581-600.

Funch, P. G., and D. S. Faber (1982) Cable properties of goldfish Mauthner axon. J. Neurophys. 47: 1196-1213.

Furshpan, E. J. (1964) Electrical transmission at an excitatory synapse in a vertebrate brain. Science $144: 878-880$.

Furshpan, E. J., and T. Furukawa (1962) Intracellular and extracellular responses of the several regions of the Mauthner Cell of the goldfish. J. Neurophysiol. 25: 732-771.

Furukawa, T., and E. J. Furshpan (1963) Two inhibitory mechanisms in the Mauthner neurons of goldfish. J. Neurophysiol. 26: 140-176.

Furukawa, T., Y. Fukami, and Y. Asada (1964) Effects of strychnine and procaine on collateral inhibition of the Mauthner Cell of goldfish. Jpn. J. Physiol. 14: 386-389.

Kaczmarek, L. K., and I. B. Levitan (1987) Neuromodulation. The Biochemical Control of Neuronal Excitability, Oxford U. P., New York.

Katz, B., and R. Miledi (1968) The role of calcium in neuromuscular facilitation. J. Physiol. (Lond.) 195: 481-492.

Kessler, J. A., D. C. Spray, J. C. Saez, and M. V. L. Bennett (1984) Determination of synaptic phenotype: Insulin and cAMP indepen- dently initiate development of electrotonic coupling between cultured sympathetic neurons. Proc. Natl. Acad. Sci. USA 81: 6235-6239.

Kohno, K., and N. Noguchi (1986) Large myelinated club endings on the Mauthner Cell in the goldfish. Anat. Embryol. 173: 361-370.

Korn, H., and D. S. Faber (1975) An electrically mediated inhibition in goldfish medulla. J. Neurophysiol. 38: 452-471.

Korn, H., and D. S. Faber (1976) Vertebrate central nervous system: Same neurons mediate both electrical and chemical inhibitions. Science 194: 1166-1169.

Korn, H., and D. S. Faber (1987) Regulation and significance of probabilistic release mechanisms at central synapses. In Synaptic Function, G. M. Edelman, W. E. Gall, and W. M. Cowan, eds., pp. 57-108, Wiley, New York.

Korn, H., A. Mallet, A. Triller, and D. S. Faber (1982) Transmission at a central inhibitory synapse. II. Quantal description of release, with a physical correlate for binomial $n$. J. Neurophys. 48: 679-707.

Korn, H., Y. Burnod, and D. S. Faber (1987) Spontaneous quantal currents in a central neuron match predictions from binomial analysis of evoked responses. Proc. Natl. Acad. Sci. USA 84: 5981-5985.

Lasater, E. M., and J. E. Dowling (1985) Dopamine decreases conductance of the electrical junctions between cultured retinal horizontal cells. Proc. Natl. Acad. Sci. USA 82: 3025-3029.

Lin, J.-W. (1986) Physiology and morphology of identified mixed excitatory synapses on the goldfish Mauthner Cell. Ph.D. Thesis, SUNY at Buffalo, Buffalo, NY.

Lin, J.-W., and D. S. Faber (1988a) Synaptic transmission mediated by single club endings on the goldfish Mauthner Cell. I. Characteristics of electrotonic and chemical postsynaptic potentials. J. Neurosci. 8 . $1302-1312$.

Lin, J.-W., and D. S. Faber (1988b) Synaptic transmission mediated by single club endings on the goldfish Mauthner Cell. II. Plasticity of excitatory postsynaptic potentials. J. Neurosci. 8: 1313-1325.

Lin, J.-W., D. S. Faber, and M. R. Wood (1983) Organized projection of the goldfish saccular nerve onto the Mauthner Cell lateral dendrite. Brain Res. 274: 319-324.

Mazliah, Y., and R. Werman (1974) The actions of glycine and GABA compared on the same cells in vertebrates. Isn. J. Med. Sci. 10:566.

Miledi, R., and R. Thies (1971) Tetanic and post-tetanic rise in frequency of miniature end-plate potentials in low-calcium solutions. $\mathrm{J}$. Physiol. (Lond.) 212: 245-257.

Nakajima, Y. (1974) Fine structure of the synaptic endings on the Mauthner Cell of the goldfish. J. Comp. Neurol. 156: 375-402.

Obaid, A. L., S. J. Socolar, and B. Rose (1983) Cell-to-cell channels with two independent regulated gates in series: Analysis of junctional channel modulation by membrane potential, calcium and $\mathrm{pH}$. $J$. Membr. Biol. 73: 69-89.

Piccolino, M., J. Neyton, P. Witkovsky, and H. M. Gerschenfeld (1982) GABA antagonists decrease functional communication between L-horizontal cells of the retina. Proc. Natl. Acad. Sci. USA 79:36713675 .

Robertson, J. D. (1963) The occurrence of subunit patterns in the unit mcmbranes of club endings in Mauthner Cell synapses in goldfish brains. J. Cell Biol. 19: 201-221.

Robertson, J. D., T. S. Bodenheimer, and D. E. Stage (1963) The ultrastructure of Mauthner Cell synapses and nodes in goldfish brains. J. Cell. Biol. 19: 159-199.

Rose, B., and R. Loewenstein (1970) Junctional membrane permeability. Depression by substitution of $\mathrm{Li}$ for extracellular $\mathrm{Na}$ and by long-term lack of $\mathrm{Ca}$ and $\mathrm{Mg}$; restoration by cell repolarization. $\mathrm{J}$. Membr. Biol. 5: 20-50.

Rose, B., and W. R. Loewenstein (1975) Permeability of cell junctions depends on local cytoplasmic calcium activity. Nature $254: 250-252$.

Saez, J. C., D. C. Spray, A. C. Nairn, E. Hertzberg, P. Greengard, and M. V. L. Bennett (1986) cAMP increases junctional conductance and stimulates phosphorylation of the 27-kDa principal gap junction polypeptide. Proc. Natl. Acad. Sci. USA 83: 2473-2477.

Schuster, M. J., J. S. Camardo, S. A. Siegelbaum, and E. R. Kandel (1985) Cyclic AMP-dependent protein kinase closes the serotoninsensitive $\mathrm{K}^{+}$channels of Aplysia sensory neurons in cell-free membrane patches. Nature 313:392-395.

Schwartzmann, G., H. Wiegandt, B. Rose, A. Zimmerman, D. BenHaim, and W. R. Loewenstein (1981) Diameter of the cell-to-cell junctional membrane channels as probed with neutral molecules. Science 213: 551-553.

Simpson, I., B. Rose, and W. R. Loewenstein (1977) Size limit of 
molecules permeating the junctional membrane channels. Science 195: 294-296.

Spray, D. C., and M. V. L. Bennett (1985) Physiology and pharmacology of gap junctions. Annu. Rev. Physiol. 47: 281-303.

Teranishi, T., K. Negishi, and S. Kato (1982) Dopamine modulates S-potential amplitude and dye-coupling between external horizontal cells in carp retina. Nature 301: 243-246.

Triller, A., and H. Korn (1982) Transmission at a central inhibitory synapse. III. Ultrastructure of physiologically identified and stained terminals. J. Neurophys. 48: 708-736.

Triller, A., and H. Korn (1986) Variability of axonal arborizations hides simple rules of construction: A topological study from HRP intracellular injections. J. Comp. Neurol. 253: 500-513.

Tuttle, R., S. Masuko, and Y. Nakajima (1986) Freeze-fracture study of the large myelinated club ending synapse on the goldfish Mauthner Cell: Special reference to the quantitative analysis of gap junctions. J. Comp. Neurol. 246: 202-211.

Werman, R., and Y. Mazliah (1978) The stoichiometry of glycine and GABA interactions with their receptors in a central neuron. In Iontophoresis and Transmitter Mechanisms in the Mammalian Central Nervous System, R. W. Ryall and J. S. Kelly, eds., pp. 400-402, Elsevier-North Holland, Amsterdam.
Wolszon, L. R., and D. S. Faber (1986) Cyclic AMP-mediated enhancement of Mauthner Cell inhibitory responses. Soc. Neurosci. Abstr. 12: 1001.

Yasargil, G. M., and J. Diamond (1968) Startle-response in teleost fish: An elementary circuit for neural discrimination. Nature 220: 241-243.

Zottoli, S. J. (1977) Correlation of the startle reflex and Mauthner Cell auditory responses in unrestrained goldfish. J. Exp. Biol. 66: 243254.

Zottoli, S. J., and D. S. Faber (1980) An identifiable class of statoacoustic interneurons with bilateral projections in the goldfish medulla. Neuroscience 5: 1287-1302.

Zottoli, S. J., A. R. Hordes, and D. S. Faber (1987) Localization of optic tectal input to the ventral dendrite of the goldfish Mauthner Cell. Brain Res. 401: 113-121.

Zucker, R. S., and L. D. Lara-Estrella (1983) Post-tetanic decay of evoked and spontaneous transmitter release and a residual-calcium model of synaptic facilitation at crayfish neuromuscular junctions. J. Gen. Physiol. 81: 355-372.

Zucker, R. S., and N. Stockbridge (1983) Presynaptic calcium diffusion and the time courses of transmitter release and synaptic facilitation at the squid giant synapse. J. Neurosci. 3: 1263-1269. 